\title{
La recuperación de los fondos fotográficos analógicos. Una competencia fundamental de los documentalistas gráficos
}

\author{
Juan Miguel Sánchez Vigil
}

\section{Resumen}

A las tradicionales tareas del documentalista gráfico, relacionadas con la selección, análisis y difusión de los contenidos, se suma ahora una específica de gran interés para los centros: la recuperación de los fondos para su uso y aplicación, un aspecto que necesita de formación técnica especializada y de criterios diseñados previamente en función de las necesidades de las empresas e instituciones públicas y privadas en lo que se refiere al contenido. Se analiza en este artículo la nueva competencia de los documentalistas gráficos para la recuperación de fondos fotográficos analógicos dentro del conjunto de trabajos que caracterizan esta profesión.

\section{Palabras clave}

Documentación, Documentación fotográfica, Documentación gráfica, Documentación informativa, Edición gráfica

\section{The Recovery of Analog Photography Collections.}

\section{A Fundamental Skill of Graphic Documentalists}

\begin{abstract}
In addition to the traditional tasks of the graphic documentalist in relation with the selection, analysis and publication of the contents, there is yet another specific aspect of great interest for the institutions: the recovery of collections for their use and digitalization, which requires a certain amount of specialized technical training and monitoring of the previously designed criteria for the contents in terms of the needs of the companies and public and private institutions. This article analyzes the new skills of the graphic documentalists for recovering the analog photography collections as part of the general work which characterizes this profession.
\end{abstract}

\section{Keywords}

Documentation, Photographic Documentation, Graphic Documentation, Informative Documentation, Graphic editing

http://dx.doi.org/10.5209/rev_CDMU.2013.v24,46287 


\section{INTRODUCCIÓN}

Entre los objetivos de las empresas dedicadas a la gestión de documentos fotográficos se encuentra la recuperación y tratamiento de sus fondos clásicos, tradicionales, o más científicamente de base química. Las investigaciones históricas sobre los siglos XIX y XX continúan centradas en los antiguos documentos, conservados en museos, archivos y bibliotecas, es por ello que el conocimiento de cuanto se relaciona con los artefactos fotográficos clásicos (cámaras, soportes y presentación de los mismos) es y será imprescindible (Kossoy, 2014: 19).

Los documentos generados mediante cámaras digitales y/o dispositivos móviles han desbordado las previsiones y expectativas por la cantidad de originales que se producen. Esta situación ha desviado durante un tiempo la atención sobre el material de archivo (papel, negativos, diapositivas, etc.), que durante años se ha conservado en carpetas, sobres y armarios. Su recuperación es una asignatura pendiente, y aunque está siendo abordada porque el material es susceptible de ser rentabilizado, la tarea es ardua, pero no solo por la cantidad sino por la calidad, lo que implica la necesidad de establecer criterios sobre lo que debe ser recuperado.

En esta última década, la tarea principal de las empresas (públicas y privadas) ha sido la adecuación a los nuevos sistemas de trabajo, siguiendo el desarrollo tecnológico. La oferta de imágenes fotográficas ya no tiene disparidad de soportes sino que se trata de ficheros digitales formados con bits o bytes de contenido específico, y el valor continúa estando en los contenidos. Por lo tanto hay que poner en valor aquellos originales que durante mucho tiempo fueron la base de la estructura de los centros de documentación, en el sentido más amplio del término.

Dichos centros disponen de fondos generales y/o especializados, demandados por una clientela variopinta (investigadores, profesionales, científicos, etc.), compuestos por millones de fotografías y pueden ser localizadas en segundos gracias a los potentes motores de búsqueda y a los gestores de imágenes, muy perfeccionados en poco tiempo, para ser aplicadas a proyectos o ideas que deben ser desarrollados mediante una lectura visual y textual o viceversa. El material lo conforman fotografías digitales y analógicas, y en este contexto los profesionales cualificados desarrollan dos funciones esenciales: el análisis de contenidos digitales y la recuperación de las fotografías para su rentabilidad. Esta última tarea es la que nos interesa en este trabajo.

Los grandes grupos editoriales, propietarios de los medios de comunicación, contaron hasta finales del siglo XX con equipos de documentalistas encargados de estas tareas; basta con pensar en la cantidad de revistas ilustradas que se distribuían cada semana o en las grandes colecciones de arte, historia, ciencia, deportes u otras materias que invaden los quioscos, o evidentemente en las webs, blogs o redes sociales.

Sin embargo, los departamentos de documentación cuentan cada vez con menos profesionales dedicados a la documentación gráfica y según los últimos estudios (García Marco, 2013; Ortiz Repiso, Virginia; Calzada Prado, Javier; Aportela Rodríguez, Ivett M., 2013; De la Moneda Corrochano, 2012) el descenso de profesionales es alarmante, sobre todo en los medios de comunicación donde debería suceder todo lo contrario por la importancia documental de la fotografía. En la práctica, determinados proyectos están siendo resueltos de manera inadecuada e incluso rechazados por no contar con documentalistas o 
profesionales capaces de dar respuesta inmediata a la recuperación de los fondos (Salvador, 2014). Las propias fototecas reciben peticiones para ilustrar contenidos cuando su función no es esa sino la de analizarlos para ponerlos a disposición del cliente.

\section{DIVERSIDAD DE TAREAS DEL DOCUMENTALISTA GRÁFICO}

El principal valor de la documentación gráfica está en la información, y por tanto en que la imagen tenga interés. El documentalista gráfico, que tradicionalmente realizaba su tarea en prensa y edición, es ahora un profesional que responde a cualquier tipo de necesidades y ante cualquier tipo de usuarios que demanden una actividad concreta (Sánchez Vigil; Salvador Benítez, 2013).

El profesional de la documentación gráfica ha evolucionado en función de los cambios socioculturales y tecnológicos. Además del conocimiento de las herramientas es imprescindible que realice una labor intelectual para la que se exige una formación que requiere el análisis de contenidos. Entre todas las actividades documentales hay una que no se ha desarrollado y que cada vez adquiere mayor importancia en aquellos centros con larga trayectoria, donde la cantidad de material no digitalizado (archivos, bibliotecas, museos, grandes medios de comunicación, editoriales, etc.) es muy alta. Se trata de recuperar fondos analógicos para su rentabilidad, siguiendo las pautas o criterios de las entidades o empresas, o bien llevando a cabo estudios a modo de informes sobre los valores de los documentos y su posible aplicación.

Identificar y clasificar contenidos para su uso es una tarea muy compleja que requiere de una gran formación cultural, así como técnica (herramientas) y científica (metodología y fuentes), en especial cuando se trata de materiales cuya producción es muy elevada, como es el caso de la publicidad (Marcos Recio; Sánchez Vigil, Olivera Zaldua, 2010). Por tanto, el origen del documentalista gráfico está efectivamente en la exigencia por parte de la industria y la investigación de un nuevo tipo de profesional de la documentación e información, demanda creciente por la necesidad de ofrecer al usuario o investigador la mayor información posible.

Es importante conocer el proceso de documentación gráfica en el que intervienen muchos factores y todos giran en torno al profesional cuya formación debe ser académica y técnica, con unas funciones generales ya conocidas (Tabla I). 
TABLA 1. PRoceso de Documentación GRÁFICA

Centro Documental

Documentalista Gráfico

FORMACIÓN

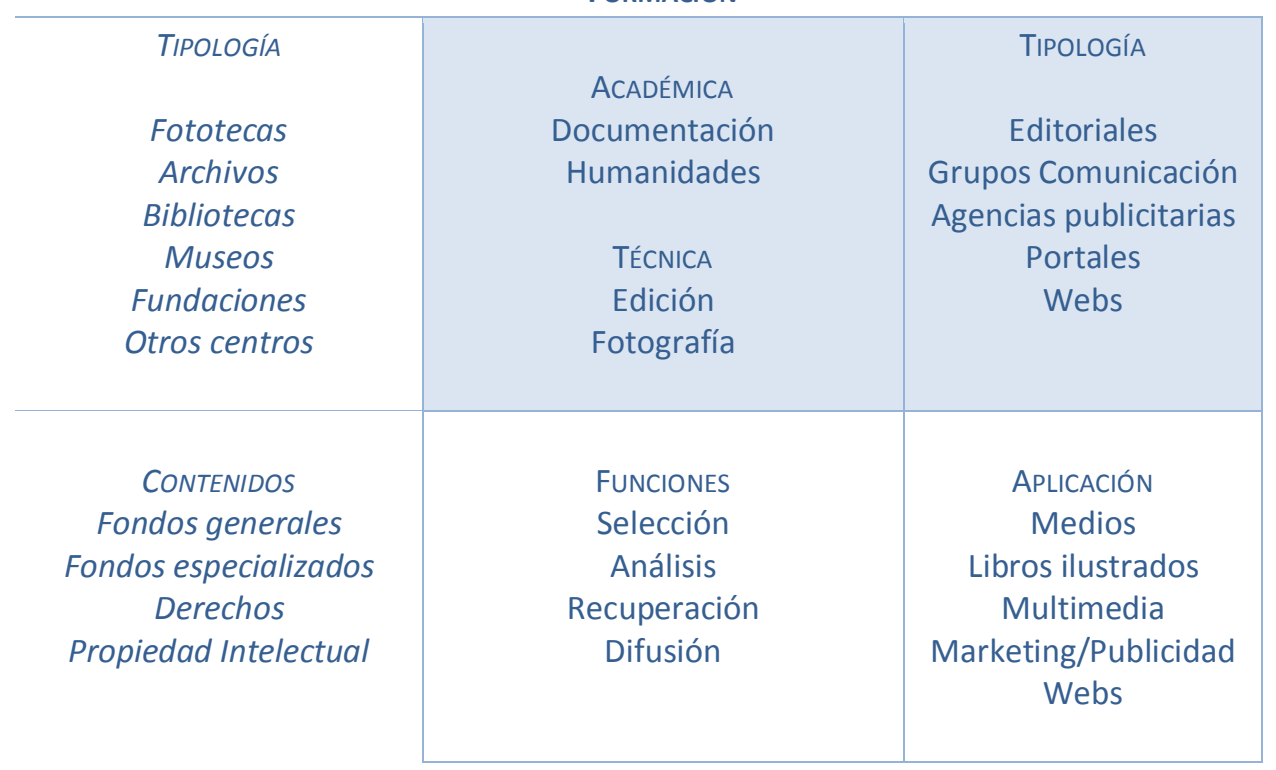

\section{El perfil profesional: formación y funciones}

La profesión de documentalista gráfico requiere de formación en dos vías: técnica y científica. La primera tiene que ver con el aprendizaje y el manejo de herramientas, la segunda sobre los conocimientos que contextualicen las tareas a desarrollar y que permitan dar una respuesta a la demanda. Para realizar sus funciones, el profesional necesita formación académica, técnica y amplios conocimientos culturales, especialización en una o varias materias, saber responder a la demanda con criterios, creatividad y originalidad, y conocer las fuentes de información.

- Formación Académica y Técnica

Grado/Licenciatura/Diplomatura en Documentación

Master en Ciencias Sociales y/o Humanidades

Estudios de Fotografía y Edición Gráfica

- Formación Complementaria

Seguimiento y análisis de información de actualidad

Conocimientos culturales: arte, historia y ciencia 


\section{Especialidad en varias materias}

- Conocimiento de los Centros y de la Fuentes de información

Agencias, bancos de imágenes y fototecas

Archivos, bibliotecas y museos

Fuentes generales y especializados

- Originalidad y Creatividad

Lectura de la imagen y análisis

Valoración y selección de contenidos

Por lo que respecta a las funciones, las principales serán la selección y el análisis, relacionado con el trabajo externo o interno; esto es con la búsqueda de material para su aplicación a proyectos o bien con el vaciado de los contenidos para obtener el máximo rendimiento de una imagen. Las funciones internas son tan amplias como las que desarrolla el centro o departamento de documentación (en este caso el archivo, la fototeca o el banco de imágenes, desde la gestión hasta el análisis. Todo ello en relación directa con el autor del documento en atención a la propiedad intelectual y los derechos (Sánchez Vigil, 2007: 213). Pocas veces el responsable del proyecto hace pública la tarea de los documentalistas, función en la que prima la creatividad. En cuanto a la lectura de la imagen, se obtendrán los descriptores o palabras clave con las que rentabilizar el fondo.

Las tareas externas se desarrollan a partir de un proyecto, en un proceso que culmina con la difusión o publicación. Son las que nos indican los nuevos retos y la formación necesaria para afrontarlos. El material del proyecto (libros, webs, enciclopedias electrónicas, etc.) depende del contenido y extensión; en ocasiones se consultan y analizan hasta diez veces más las fotografías necesarias para obtener un solo original aplicable. Los profesionales advierten que la burocracia, la desorganización interna y ausencia de criterios influye negativamente en los tiempos de respuesta.

\section{RECUPERACIÓN DE LOS FONDOS. ACTUACIONES Y CRITERIOS}

La recuperación de los fondos es fundamental para la rentabilidad cultural y/o económica de los mismos. La mayoría de los centros con fondos fotográficos antiguos han realizado un gran esfuerzo para digitalizar sus colecciones, si bien solo una mínima parte han sido difundidos, como sucede con los grandes diarios, agencias, bancos de imágenes y fototecas nacionales e internacionales. En el diario $A B C$, en la agencia EFE o en la fototeca Roger Viollet, con cerca de treinta millones de fotografías, apenas un $10 \%$ ha sido digitalizado para la comercialización (Figuras 1 y 2 ). 


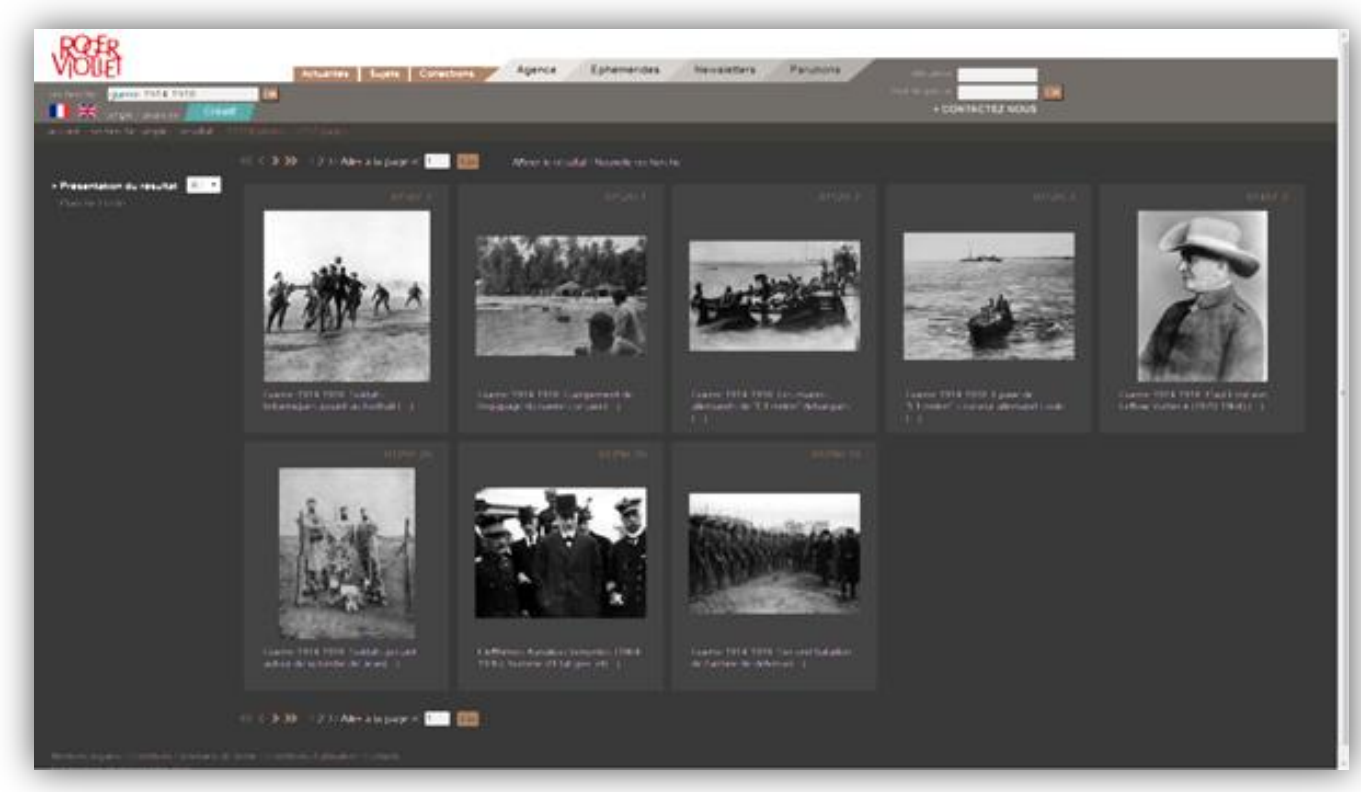

Figura 1. Fototeca Roger Viollet (www.rogerviollet.fr.)

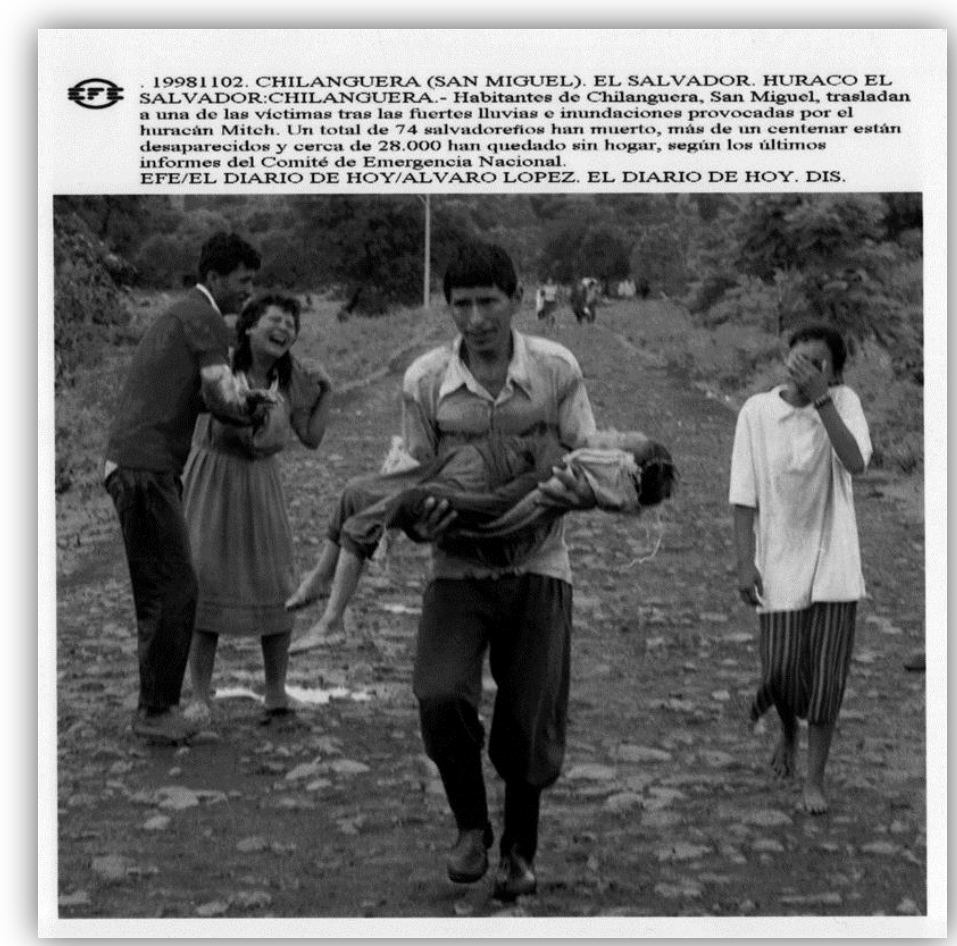

Figura 2. Fotografía de la agencia EFE

(Original en color, www.efe.es) 
Se contemplan dos aspectos generales en la recuperación de los fondos: por un lado las actuaciones a llevar a cabo para conseguir los mejores resultados, y por otro los criterios a considerar en función de los objetivos trazados. Actuaciones y criterios deben combinarse, ya que no siempre son coincidentes.

\section{Actuaciones}

La propuesta para la recuperación se estructura en cuatro estadios o etapas, con una línea de trabajo que comienza en la selección y finaliza con la catalogación del documento o documentos seleccionados:

1. Selección de originales

Dada la gran cantidad de originales preservados en los centros de documentación pública (archivos, bibliotecas, museos, fundaciones, institutos, etc.), así como en las empresas privadas, se plantea la necesidad de una revisión exhaustiva de todos y cada uno de los temas, con el fin de responder a las necesidades. Se deben tener en cuenta:

a. La calidad de los originales, de la que dependerá la decisión final.

b. La cualidad, es decir el original de mayor interés, no solo para la aplicación inmediata sino a medio y largo plazo.

2. Análisis de contenidos

La formación del documentalista para llevar a cabo esta tarea es clave, puesto que deberá relacionar el documento con los objetivos planteados en la búsqueda y recuperación de la información contenida. Es imprescindible la lectura de la imagen para obtener todo cuando sea de interés para el hipotético investigador o para los objetivos prefijados por la institución o empresa. Se deben tener en cuenta:

a. Los descriptores onomásticos, geográficos, cronológico y de materia

b. El resumen o descripción de la imagen

3. Reproducción de los originales

La formación técnica, independientemente de que las operaciones de escaneado o toma de imágenes las realice un profesional especialista en el tema, es clave en este punto. Deben conocerse los resultados en función del uso de los dispositivos (escáner o cámara), con el fin de tomar decisiones al respecto. Se tendrán en cuenta:

a. Los modelos de escáneres adecuados para la reproducción de originales fotográficos (resolución y óptica)

b. Las cámaras fotográficas (resolución, óptica, formatos, etc.)

4. Catalogación

Una vez seleccionado, analizado y reproducido el material, la información obtenida debe plasmarse en los registros adecuados a través del programa de gestión previsto con el fin de que su recuperación sea posible. Se debe tener en cuenta:

a. Gestión de contenidos (norma de catalogación)

b. Sistemas de difusión de los mismos 


\section{Criterios}

El conocimiento del medio y de las funciones de la empresa o institución para la que se realice la recuperación de los fondos permite llevar a cabo un estudio previo de los originales, de tal forma que una misma fotografía pueda tener diferentes aplicaciones si previamente es analizada y se obtienen los descriptores adecuados para la posible reutilización. En la práctica supone que puede no ser necesario reproducir fotografías completas, sino detalles, cuando el tema no se ajusta a los objetivos finales. En consecuencia se tendrán en cuenta los siguientes criterios:

- Actividad principal o especialización de la institución, la empresa o el departamento de documentación. El proyecto en el que se trabaje y sus contenidos (página web, libro ilustrado, blog, etc.) marcará la pauta para decidir que originales han de ser recuperados para su digitalización.

- Presupuesto, De la inversión económica dependerá la decisión en uno u otro sentido. Pueden recuperarse materiales cuya digitalización implique una reducida inversión o bien todo lo contrario. Un factor importante es este apartado es la característica del original: soporte (placas de vidrio, diapositivas, papel, etc.) y formato $(35 \mathrm{~mm}, 9 \times 12,13 \times 18,24 \times 30 \mathrm{~cm}$, etc.).

- Rentabilidad. La lectura de este criterio se realizará desde dos puntos de vista: cultural y/o económico. Se relaciona directamente con el presupuesto y debe considerarse a corto, medio o largo plazo.

- Calidad del original. En este caso el criterio dependerá del estado en que se encuentre el material a digitalizar. No se trata solo del tipo (soporte o formato) sino de las dificultades para la digitalización cuando su estado físico no es bueno. En este caso se marcarán prioridades.

\section{CONCLUSIONES}

Los fondos fotográficos analógicos en las instituciones públicas o privadas constituyen un patrimonio cultural que ha dejado de utilizarse tras el cambio tecnológico al generarse los nuevos documentos digitales. Ello ha supuesto la pérdida o discriminación de conjuntos documentales de gran valor cuya recuperación puede y debe plantearse con inmediatez.

Las bibliotecas, archivos, museos, institutos, fundaciones y otros centros con funciones similares disponen de fondos fotográficos de los siglos XIX y XX cuyos soportes y técnicas deben estudiarse para obtener una mayor rentabilidad cultural y/o económico en el proceso de recuperación de los mismos.

Este nicho de originales, que en otro tiempo fue tratado y estuvo disponible de acuerdo a unas técnicas, conforma actualmente un patrimonio invisible muy superior en cantidad al digital, teniendo en cuenta que la producción con cámaras digitales comenzó hace una década.

Los profesionales de la documentación deben ser los responsables de la recuperación de los fondos fotográficos analógicos (de base química), haciendo de esta tarea una de sus competencias y habilidades, interviniendo en el sentido de fijar los criterios y actuaciones para obtener los mejores resultados.

Por último, las tareas de recuperación de los fondos requieren de planes de actuación y criterios muy concretos, que deben prefijarse y valorarse detalladamente, es decir que se deben aplicar de acuerdo a los objetivos generales de las instituciones o de los proyectos de las mismas. 


\section{Referencias bibliográficas}

De la Moneda Corrochano, Mercedes (2012). "Las cifras de la enseñanza en documentación en España: 2010", en Anuario ThinkEPI, v. 6, pp. 13-30.

García Marco, Francisco Javier (2013). “Educación y aprendizaje de la información y la documentación: raíces, desafíos y líneas de acción”, en El Profesional de la Información, noviembre-diciembre, vol. 22, n. 6, pp. 489-504.

Iglesias, David (2008). “El perfil profesional de l'arxiver especialista en fotografía”, en Imatge i Recerca. 10 Jornadas Antoni Varés. Girona: Ajuntament, pp. 79-90.

Kossoy, Boris (2014). Lo efímero y lo perpetuo en la imagen fotográfica. Madrid: Cátedra.

Marcos Recio, Juan Carlos; Sánchez Vigil, Juan Miguel; Olivera Zaldua, María (2010).

“Modelos de gestión documental en las agencia de publicidad", en el Profesional de la Información, 19-2, PP. 175-183.

Ortiz Repiso, Virginia; Calzada Prado, Javier; Aportela Rodríguez, Ivett M. (2013). “Qué está pasando con los estudios universitarios de biblioteconomía y documentación en España", en El Profesional de la Información, septiembre-octubre, v. 22. n. 6, pp. 505-514.

Salvador Benítez, Antonia (Coordinadora, 2014). Patrimonio fotográfico. De la visibilidad a la gestión. Gijón: Trea (en prensa).

Sánchez Vigil, Juan Miguel (2007). El documento fotográfico. Gijón: Trea

Sánchez Vigil, Juan Miguel; Salvador Benítez, Antonia (2013). Documentación fotográfica. Barcelona: UOC. 